\title{
Adhesive wear mechanism under combined electric diamond grinding
}

\author{
Vyacheslav Popov ${ }^{1, *}$, Pavel Arkhipov ${ }^{1}$, and Daniel Rychkov ${ }^{1}$ \\ ${ }^{1}$ Bratsk State University, 40 Makarenko, Bratsk, 665709, Russian Federation
}

\begin{abstract}
The article provides a scientific substantiation of loading of metal-bond diamond grinding wheels and describes the mechanism of contact interaction (interlocking) of wheels with tool steel as well as its general properties having an influence on combined electric diamond grinding efficiency. The study concluded that a loaded layer can be formed in a few stages different by nature. It is known, that one of the causes of grinding degradation is a continuous loading of active grits (abrasive grinding tool) by workpiece chips. It all affects the diamond grinding wheels efficiency and grinding ability with a result in increase of tool pressure, contact temperature and wheels specific removal rate. Science has partially identified some various methods to minimize grinding wheel loading, however, as to loading of metal-bond diamond grinding wheels the search is still in progress. Therefore, research people have to state, that in spite of the fact that the wheels made of cubic boron nitride are of little use as applied to ceramic, ultrahard, hardalloyed hard-to-machine and nano-materials of the time, but manufactures have to apply cubic boron nitride wheels wherein diamond ones preferable.
\end{abstract}

\section{Introduction}

Loading is an adhesion of grinding dust (chips out of workpieces, tools, lubricoolant, etc.) to the active grits during the abrasive machining [1-7]. A dressing process is needed to remove worn grains, to disclose new and sharp grains and to restore the geometry of cutting face of the wheel [8-18]. Currently, they have ascertained the nature of chip adhesion as adhesive and diffusive one. In order to provide its scientific justification it is needed to widen and deepen the scope of investigation: from macro and through micro to an atomic level [19]. We developed a theory of wheel loading $[20,21]$. It has been placed beyond a doubt that a loading layer has a complex, mechanic and physicochemical nature and consists of workpiece components, wheel bond, secondary compounds formed as a result of adhesive and diffusion phenomenon, chemical reaction including recrystallization. Mathematical modeling of contact interaction was carried out on a micro level. The necessary prerequisites were created for modelling (simulation) objects on an atomic level [22].

\section{Experimental investigation procedure}

Investigation procedure of diamond grinding wheels (DGW) surface after combined electric diamond grinding (CEDG) was aimed to identify a radial component of cutting pressure, $\mathrm{P}_{\mathrm{y}}\left(\mathrm{N} / \mathrm{cm}^{2}\right)$; cutting power efficiency, $\mathrm{N}_{\mathrm{ef}}(\mathrm{W})$. Artificial thermocouple was used to take contact temperature in the grinding area. A scanning electron microscopy, SEM (Carl Zeiss
$\mathrm{EVO}^{\circledR} 50 \mathrm{XVP}$ ) was used to get images of metalic bond DGW surfaces. Microrelief parameters were identifired by an optical interferometry (Zygo NewView ${ }^{\mathrm{TM}} 7300$ ). Chemical composition of DGW surfaces was identifired by an Energy-Dispersive X-ray Analysis (Oxford Instruments) and a phase structure of DGW surfaces was recieved with the help of X-ray structural analysis (ARL X'TRA (Thermo Fisher Scientific)) [20].

\section{Investigation of relationship (dependence) of radial cutting pressure and cutting power efficiency}

Investigation of dependence of a radial cutting pressure (Fig. 1) and a cutting power efficiency (Fig. 2) from CEDG operating modes reviels that machining force (cutting pressure) at diamond grinding as applied to high-speed steel (HSS) is 3-5 times higher than when grinding hard alloys due to an intence diamond-steel interaction (interworking). Therfore, by the nature of tool-load change, one can inderectly judge some phisical phenomena occured in the cutting area. Under certain electrical $\left(i_{\text {ed }}, i_{\text {et }}\right)$ and mechanical $(S, V, t)$ machining conditions, one can achieve the following goals: set up a self-sharpening mode on DGW; block its loading; stabilize the cutting power at its minimum power value.

\section{Investigation of temperature in contact zone}

\footnotetext{
Corresponding author: berkutoff $@$,rambler.ru
} 
Investigation of the contact temperature in the cutting zone (Fig. 3) shows that a thermal conduction of HSS is poor and get hot very fast during grinding. High temperature appears to be an accelerator in the process of plastic deformation, formation of a defect layer and some other contact actions [23-25], as well as it intencifies crack formation along the tool nose (cutting edge), with its further failure.

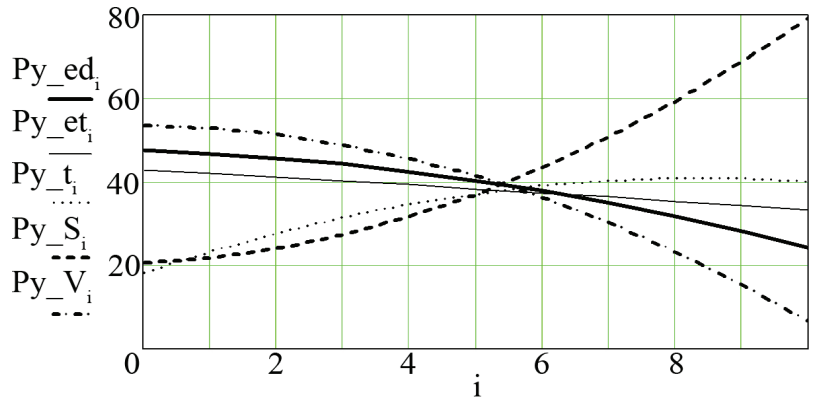

Fig. 1. Graphical relationship (dependence) of radial cutting pressure $\mathrm{P}_{\mathrm{y}}$ on CEDG operating modes

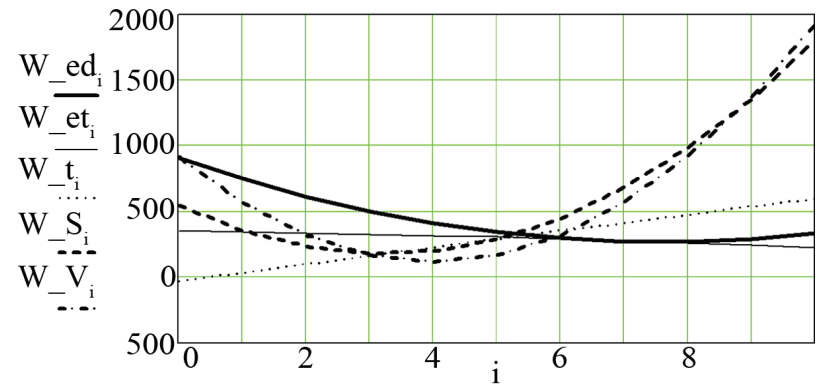

Fig. 2. Graphical relationship (dependence) of cutting power efficiency $\mathrm{W}$ on CEDG operating modes

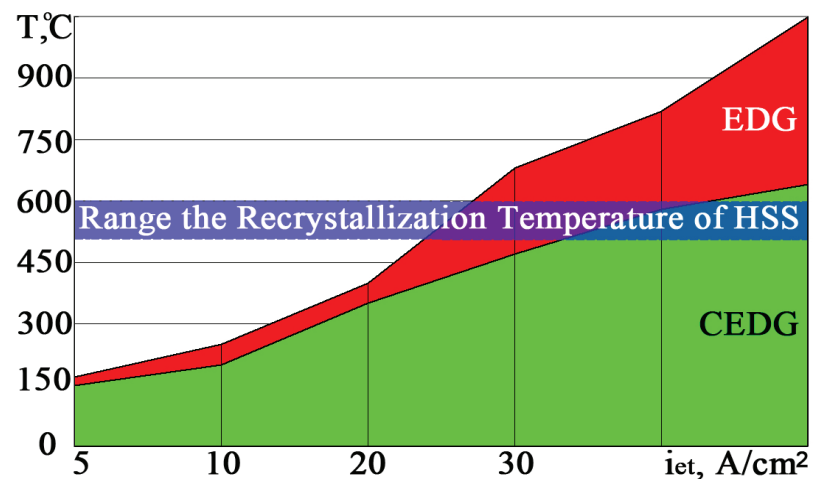

Fig. 3. Temperature in the Contact Zone

Therefore, it is practically impossible to apply a common way of machinning to hardened HSS, taking into account that the temperature in the contact zone can be about $1200^{\circ} \mathrm{C}$. At CEDG and under the recommended conditions the temperature appears $150-180^{\circ} \mathrm{C}$ only that does not bring to recrystallization of HSS components (recrystallization temperature for components: $\mathrm{Fe} 450^{\circ} \mathrm{C}$, Cr $850-1075^{\circ} \mathrm{C}, \mathrm{W} 1200^{\circ} \mathrm{C}, \mathrm{V} 700-800^{\circ} \mathrm{C}$, Mo $850-$ $1220^{\circ} \mathrm{C}$ ). This is a good showing [26-29], so far as high hardness of the tool made of HSS remains its quality upon heating up to $500-600^{\circ} \mathrm{C}$. On the whole, a tool being sharpened under CEDG will remain cold when the heat load falls only on the thin upper layer which is being removed while machining.

\section{Energy-Dispersive X-ray analysis (Oxford Instruments)}

Energy-Dispersive X-ray Analysis of chemical composition of the loaded layer (Fig. 4) revealed that a diffraction pattern has planty of weak reflections that is typical of inorganic matters containing essential amount of different phases. In addition, poor quality of diffraction patterns at the statistical accuracy of $5 \mathrm{sec}$. indicates a high content of crystal defects in the present patterns [30]. Spectral analysis of surface X-Ray patterns was carried out and decoded. (Fig. 5, b). Components of $\mathrm{Fe}, \mathrm{Al}, \mathrm{Cu}, \mathrm{Zn}, \mathrm{Mg}, \mathrm{O}, \mathrm{C}$ in the patterns were found according to the results of the chemical analysis.

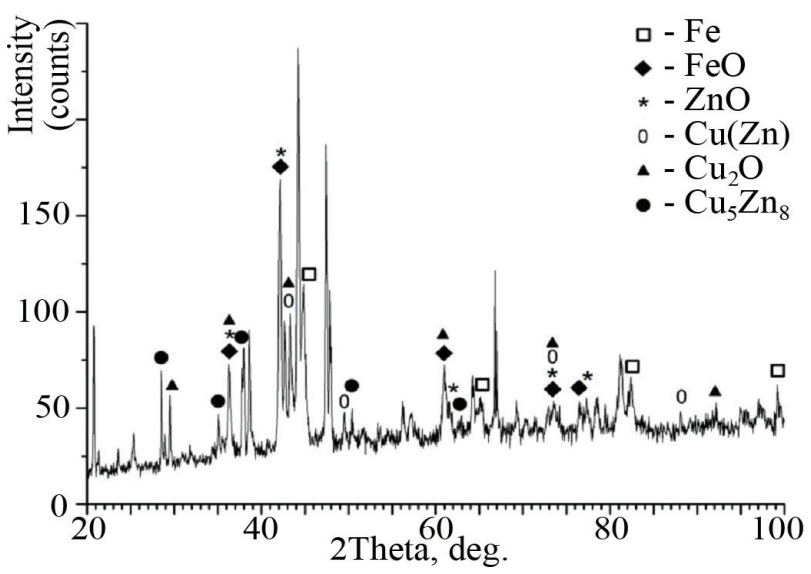

Fig. 4. Analysis of the DGW surface diffraction pattern after CEDG HSS

It should be observed that during the formation of a loaded layer, as well as a defect one when grinding without lubricoolant, the heat factor is of primary importance. Exactly heat appears to be the key initiator of physical and chemical phenomena and reactions. In each case when machining and grinding different materials with different abrasives, there can arise different adhesion mechanisms which are more relevant to a specific thermodynamic, phase or kinetic process (Fig. 5).

Mechanical adhesion (Fig. 5, a).

At the very beginning of grinding, when grits just begin scratching agaist the material, then a mechanical adhesion interlocking of chips between grits and metalbond DGW takes place. Thence arise surface residual compressive stresses. It makes possible to minimize loading and save high cutting abilities of DGW by lubricoolant feed speed up or by reducing the depth of cut, besides the correct selection of grinding tool specification. 


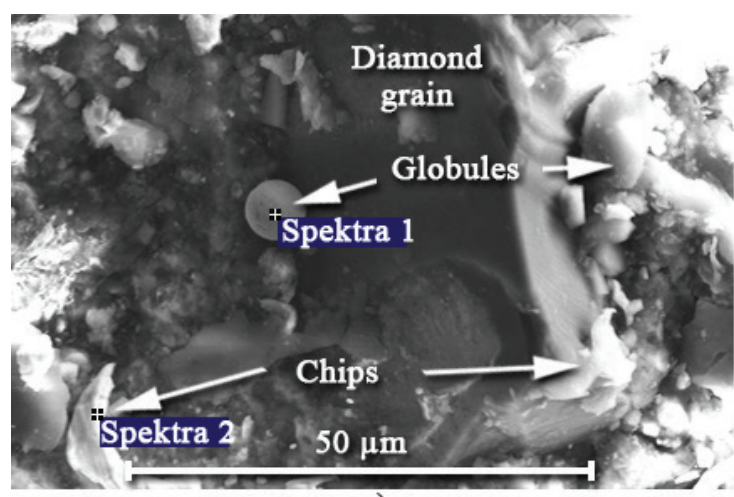

a)
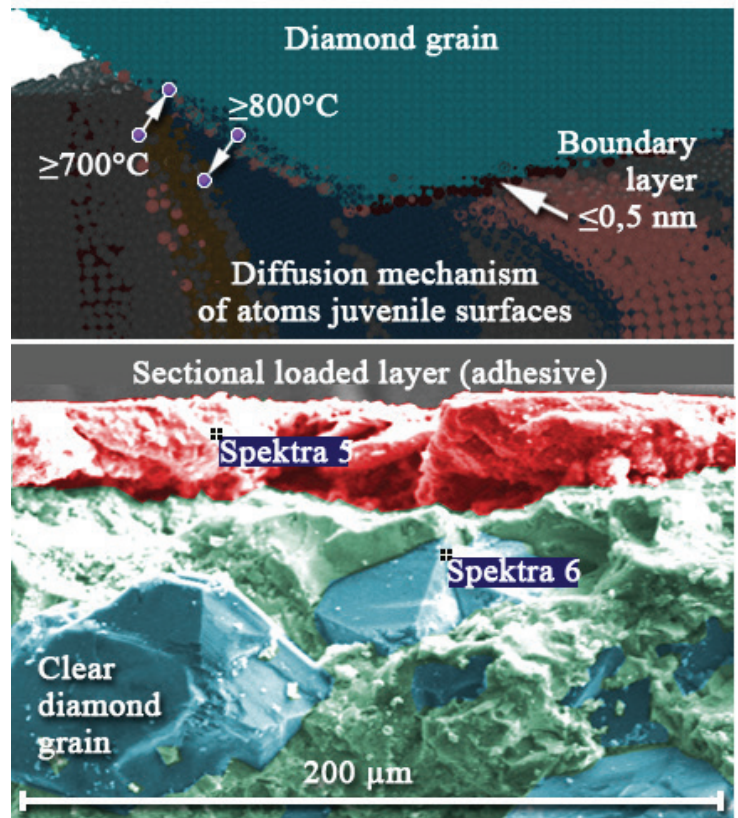

c)

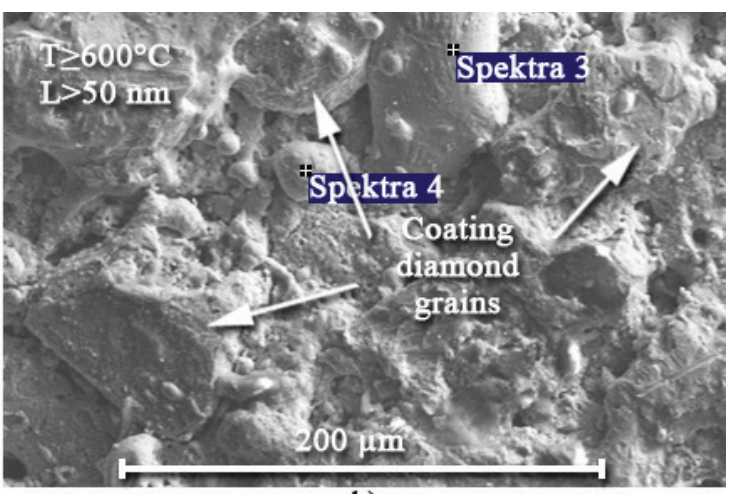

b)

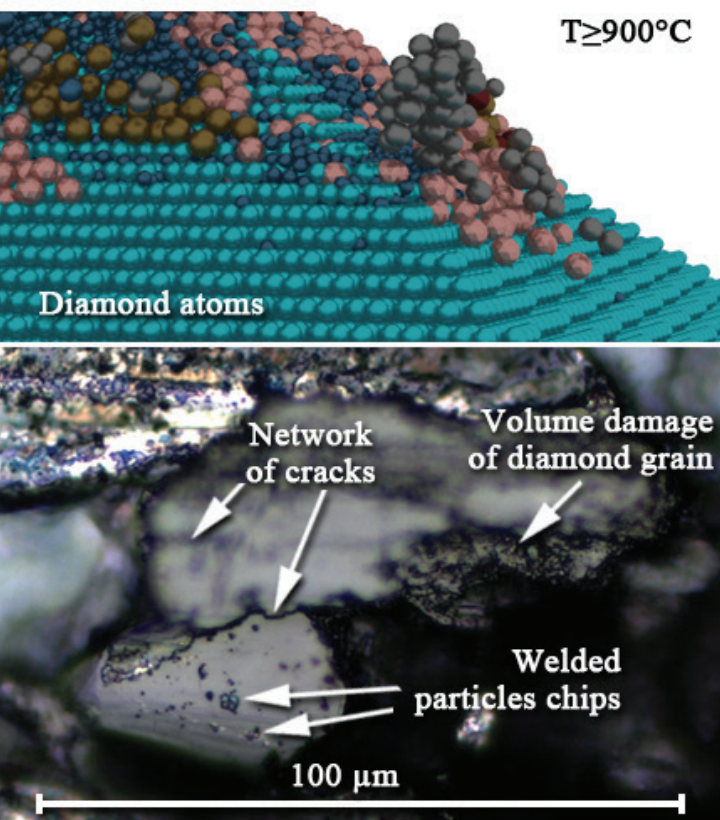

d)

Fig. 5. Mechanism of contact interaction under CEDG: a) mechanical adhesion; b) molecular adhesion; c) chemical adhesion; d) electrical adhesion

Grinding wear of grits, typical to mechanical adhesion, lays in localized microdistruction of cutting grits and thier chipping due to tearing of a sticking stuff off periodically. As a rule, the rate of loading is higher when cutting plastic materials and it tends to tearing right up to the bond level when cutting some breakable materials. This affects the grinding material in a form of negative changes in the surface layer due to ecrease of cutting force. The risk of thermal damages to the surface increases significantly.

Adsoptive or molecular adhesion (Fig. 5, b).

Chip gradual accumulation results in its packing between grits and in DGW bonds that leads to a pressure boost. This makes an adsoption to be diffused all over the active surface, which in turn goes with a heat release. Surface residual compressive stresses are generated creating favourable conditions for a phisical adsoption inside cracks of plastically deformed material (chips). Worn sports on the surface of grits are progressing; a constant friction involves grits in an additional air oxidation that results in chips of greater size.

Molecular adhesion process can be compensated by use of emulsions and oils, creation of inert atmosphere or adding a special active admixture to a lubricoolant. The literature, in this stage of loading, recommends to replace a diamond abrasive (grit) with an el'bor borazon, silicon carbide or more porous abrasive tool.

Simultaneous increase in cutting tool force (Fig. 1), cutting power (Fig. 2) and temperature (Fig. 3) in the contact zone results in formation of burnings on the machining surface. Carbide grits start to grow making the machining surface more scored and rough.

Chemical adhesion (Fig. 5, c).

Further increase in pressure and temperature due to a significant contact area extension is the reason of the formation of an interfacial (interphase) contact (Fig. 4). The phase transformation brings to the compressive or streching surface stresses, subject to a gain or reduction of the transfered material phase volume. By this time both loaded and machining surfaces are juvenile. Thermodynamic preconditions arise for a Van-der-Vaals interaction, i.e. chemical bonding, that is more appropriate for the materials of the same chemical nature. The chemical adhesion compound, since its formation, can save its integrity and high mechanical properties in spite of external action or corrosive medium. From now on, the ready-built bond is the most difficult to destroy in usual way. The only way to remove a loaded layer is a mechanical tear of chemical bonds by various technique of DGW trimming or a 
combined machining approach. As a result of the chemical adhesion a DGW wear encreases significantly and whole grits have been torn out yet. Some irreversible structural changes occur in the machining material which are considered a waste.

Electrical adhesion (Fig. 5, d).

If the above mentioned conditions should be observed during the machining process thence arises simultanious plastical deformation both in the machining surface and the loading layer. This deformation includes all three types: mechanical,themal and phase one. But if grinding is carried out by a combined method, with electric current bringing in additionally into machining zone, then wheel loading might be as well due to sticking of grinding dust and grits. Temperature increase might be observed in the DGW bonds that results in grits cracking along ruptures under the heat impact.

\section{Results and discussion}

In terms of the mentioned above as well as of results of complex research of CEDG tool steel, it seams possible to create such conditions which be able to prevent DGW loading and widen process possibility of their application in elctrical and chemical treatment. It will allow to reach a new and competitive production level [31].

\section{Conclusions}

As a result of analitical and experimental research, an urgent scientific issue has been addressed. This up to date goal is of great economic worth that makes it possible to discover qualitative patterns of relationship of matal-bond DGW loading mechanism subject to the specified thermodynamic phase and kinetic properties of grinding.

Formation of a loaded layer on the surfaces of DGW under impact of high temperature, pressure and interatomic interaction has been well-grounded and corroborated by methods of spectral, X-Ray energodispersive analysis and raster electronic microscopy. The chemical composition of a loaded layer has been identified with the help of analyses mentioned above. The nature of DGW loading has been identified as adhesive-diffusive which takes place at grinding tool iron-carbon steel at the expense of carbon diffusion. As a result there is a breakable overstrengthened structure with a heightened microhardnees. All this affect the upper layer and decrease its mechanical properties.

The reported study was funded by RFBR according to the research project No. 16-38-00123 мол_а.

\section{References}

1. W.B. Rowe, 2nd ed. Oxford: Elsevier, (2014)

2. J. Badger, S. Murphy, G.E. O'Donnell, AMR, 126128, 597-602, (2010)

3. S. Malkin, Guo Changsheng, New York, Industrial Press, (2007)
4. M.J. Jackson, J.P. Davim, Springer US, (2011)

5. I.D. Marinescu, M.P. Hitchiner, E. Uhlmann, W.B. Rowe, I. Inasaki, CRC Press, (2016)

6. R.I. King, R.S. Hahn, Springer Science \& Business Media, (2012)

7. H.G. Sachsel, C.A.E. Precision, Xlibris Corporation, (2010)

8. M. Schöpf, I. Beltrami, M. Boccadoro, D. Kramer, CIRP AMT, 50 (1), 125-128, (2001)

9. E. Brinksmeier, Y. Mutlugunes, F. Klocke, J.C. Aurich, P. Shore, H. Ohmori, CIRP AMT, 59 (2), 652-671, (2010)

10. A.G. Mamalis, M. Horvath, A.I. Grabchenko, J. MPT, 97 (1-3), 120-125, (2000)

11. J.B.J.W. Hegeman, J.Th.M. De Hosson, G. De With, Wear, 248 (1-2), 187-196, (2001)

12. C.C. Chang, A.Z. Szeri, Wear, 216 (1), 77-86, (1998)

13. B. Zhang, X.L. Zheng, H. Tokura, M. Yoshikawa, J. MPT, 132 (1-3), 353-364, (2003)

14. H. Hamdi, H. Zahouani, J.M. Bergheau, J. MPT, 147 (3), 277-285, (2004)

15. P. Durgumahanti, V. Singh, R.P. Venkateswara, Inter. J. MTM, 50 (3), 231-240, (2010)

16. Z. Zhang, F. Huo, Y. Wu, H. Huang, Inter. J. MTM, 51 (1), 18-24, (2011)

17. X. Chen, W.B. Rowe, R. Cai, Inter. J. MTM, 42 (5) 585-593, (2002)

18. J. Webster, M. Tricard, CIRP AMT, 53 (2), $597-$ 617, (2004)

19. V.Y. Popov, A.S. Yanyushkin, Eas. Eur. Scien. J. 2, 301-310, (2014)

20. V.Yu. Popov, A.S. Yanyushkin, Y.I. Zamashchikov, AMM, 799-800, 291-298, (2015)

21. D.V. Lobanov, P.V. Arkhipov, A.S. Yanyushkin, V.Yu. Skeeba, IOP Conf. Ser.: MSE, 142, 012081, (2016)

22. V.Y. Popov, A.N. Khlystov, A.V. Bondin, CRM, 8 (1), 161-172, (2016)

23. V. Ivancivsky, K. Parts, V. Popov, AMM, 788, 129-135, (2015)

24. V.Yu. Skeeba, V.V. Ivancivsky, N.V. Martyushev, D.V. Lobanov, N.V. Vakhrushev, A.K. Zhigulev, KEM, 712, 105-111, (2016)

25. V.Yu. Skeeba, V.V. Ivancivsky, A.V. Kutyshkin, K.A. Parts, IOP Conf. Ser.: MSE, 126, 012016, (2016)

26. Hossam Halfa, J. MMCE, 1, 257-270, (2013)

27. V.Yu. Skeeba, V.V. Ivancivsky, D.V. Lobanov, A.K. Zhigulev and P.Yu. Skeeba, IOP Conf. Ser.: MSE, 125, 012031, (2016)

28. L.A. Bokhoeva, V.E. Rogov, A.S. Chermoshentseva, D.V. Lobanov, IOP Conf. Ser.: MSE, 142, 012077, (2016) 
29. V.V. Ivancivsky, V.Yu. Skeeba, I.A. Bataev, D.V. Lobanov, N.V. Martyushev, O.V. Sakha, I.V. Khlebova, IOP Conf. Ser.: MSE, 156, 012025, (2016)

30. J.H. Chen, D. Bernaerts, J.W. Seo, G. van Tendeloo, H. Kagi, Mag. Let., 77 (3), 135-140, (1998)

31. A.S. Yanyushkin, D.V. Lobanov, D.A. Rychkov, AMM. 770, 739-743, (2015) 